Textures and Microstructures, Vol. 30, pp. 125-132 Reprints available directly from the publisher Photocopying permitted by license only
(C) 1998 OPA (Overseas Publishers Association) N.V. Published by license under the Gordon and Breach Science Publishers imprint. Printed in India.

\title{
HIGH TEMPERATURE TEXTURE GONIOMETER FOR IN SITU MEASUREMENTS OF TRANSFORMATION TEXTURES
}

\author{
G. BRÜCKNER, F.R. REHER* and G. GOTTSTEIN \\ Institut für Metallkunde und Metallphysik, RWTH Aachen, \\ Kopernikus Str. 14, D-52074 Aachen, Germany
}

(Received 6 September 1996)

\begin{abstract}
A high temperature stage was designed for mounting onto a computer controlled four circle X-ray texture goniometer. This technique allowed to conduct in situ texture measurement, i.e. the determination of the texture evolution during rather than subsequent to annealing. The device was employed for temperatures up to $1000^{\circ} \mathrm{C}$.

The furnace consisted of a resistance wire of $\mathrm{Pt} 30 \mathrm{Rh}$, which was isolated against the specimen with $\mathrm{Al}_{2} \mathrm{O}_{3}$ glue. The furnace with the specimen was covered by a hemispherical Kapton $^{\mathrm{TM}}$ foil. Inside the hemisphere a reducing gas atmosphere was used to avoid oxidation of the sample surface.
\end{abstract}

Keywords: Transformation texture; High temperature texture measurement

\section{INTRODUCTION}

The $\alpha \rightarrow \gamma$ phase transformation has been the subject of investigations for quite a long time, e.g. Bain published 'The Nature of Martensite' already in 1924 (Bain, 1924). The phase transformation of the most commercial steels occurs at high temperatures. Because of the experimental difficulties associated with the measurement of $\mathrm{X}$-ray textures at elevated temperatures, there is virtually no information on austenite textures of commercial steel. For recording X-ray textures at high temperatures an existing four circle texture goniometer as described by

\footnotetext{
* Corresponding author
} 
Hirsch et al. (1986) was modified (Reher et al., 1994). This allowed the determination of textures at different temperatures in one sample and therefore detailed investigations of e.g. transformation textures.

\section{CONSTRUCTION}

The furnace was heated with a $\varnothing 0.5 \mathrm{~mm} \mathrm{Pt} 30 \% \mathrm{Rh}$ resistance wire, which allowed a wire temperature of up to $1500^{\circ} \mathrm{C}$. The wire, bent to a spiral, was inserted in a ceramic body (Fig. 1). The density of the loops decreased towards the centre of the furnace in order to obtain a homogeneous specimen temperature. The electrical contact of sample and resistance element was prevented by covering the wire with $\mathrm{Al}_{2} \mathrm{O}_{3}$ glue in the ceramic body.

To avoid damage to the Euler cradle due to thermal expansion or degradation of the lubricating grease, the temperature of the cradle should not exceed $180^{\circ} \mathrm{C}$. Therefore, the heat conduction to the Euler cradle was minimized by fastening the furnace onto low density ceramic pins, which were placed on aluminium cooling fins. This assembly kept the cradle temperature below $120^{\circ} \mathrm{C}$ even at maximum furnace power.

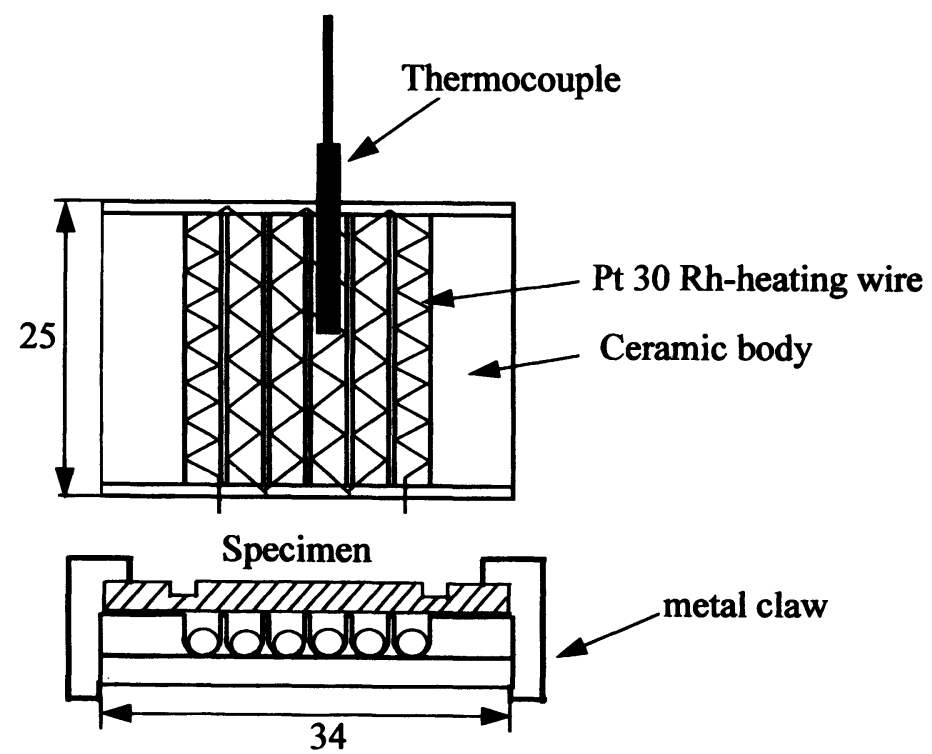

FIGURE 1 Schematic arrangement of the resistance element. 
The specimen $\left(35 * 24 \mathrm{~mm}^{2}\right)$ was clamped down onto the furnace with metal claws (Fig. 1). The measuring surface of the sample was $14 * 24 \mathrm{~mm}^{2}$. A Pt-Pt10Rh thermocouple, which measured the temperature in the heating spiral was connected to a temperature controller. This controller itself was programmed and monitored by a computer, which set the entire thermal cycle for the experiment. This design allowed a quick and easy specimen change without changing the thermocouple. Further optional thermocouples attached to the specimen were used to calibrate the furnace. Specimen temperatures in the centre and at the edge were measured and plotted as a function of the wire temperature in Fig. 2. The temperature gradients in the specimen were found to be less than $15^{\circ} \mathrm{C}$. The temperature in the wire and in the specimen differed by about $250^{\circ} \mathrm{C}$ at maximum furnace power.

The furnace with the specimen was covered by a hemispherical Kapton $^{\mathrm{TM}}$ foil with a thickness of $70 \mu \mathrm{m}$. The hemisphere had been produced by deep drawing at $400^{\circ} \mathrm{C}$. The spherical shape ensured a constant absorption of the X-ray beam for all angular positions. The intensity loss due to the foil was measured for different temperatures. In Fig. 3 the reflected intensities of the $\{110\}$ crystallographic planes were measured in a $\vartheta$-scan with and without the foil at room temperature

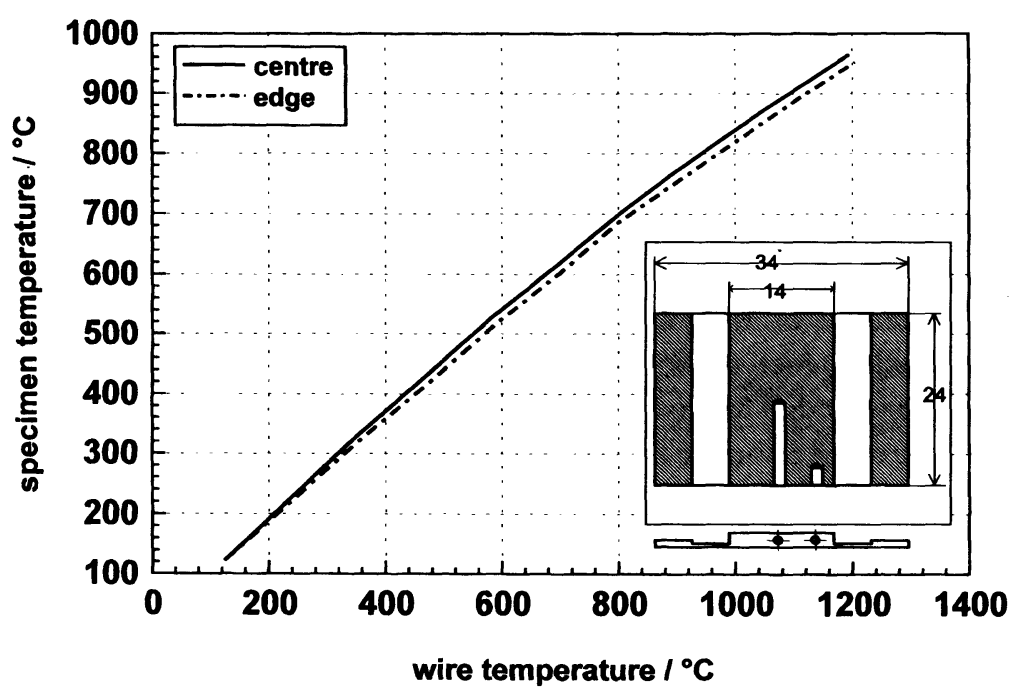

FIGURE 2 Specimen temperature as a function of the heating wire temperature. Temperature gradients in the specimen did not exceed $15^{\circ} \mathrm{C}$. 


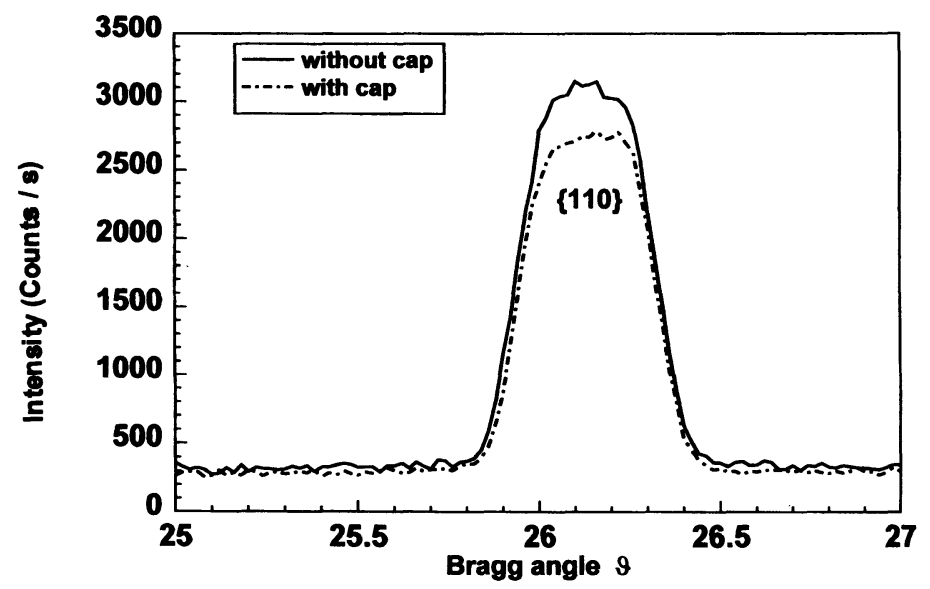

FIGURE $3\{110\}$ reflection peak of low carbon steel with and without Kapton ${ }^{\mathrm{TM}}$ foil at $T=25^{\circ} \mathrm{C}, \mathrm{CoK}_{\alpha}$-radiation. The intensity loss is about $10 \%$.

with $\mathrm{CoK}_{\alpha}$-radiation. The $\mathrm{X}$-ray intensity loss was found to be approximately $10 \%$. The same result was obtained at $500^{\circ} \mathrm{C}$.

Within the hemisphere a reducing gas atmosphere with a flux of about $5 \cdot 10^{-3} \mathrm{~m}^{3} / \mathrm{h}$ had to be used to avoid oxidation of the sample surface. For the first experiments a $\mathrm{N}_{2}$ atmosphere was used. Because of the residual oxygen in the hemisphere the sample suffered strong oxidation, which could be measured in a $\vartheta$-scan of the austenitic phase of a low carbon steel at $950^{\circ} \mathrm{C}$ (Fig. 4(a)). An addition of $5 \% \mathrm{H}_{2}$ reliably prevented an oxidation of the specimen (Fig. 4(b)).

In the Euler cradle the electrical wires and the gas supply of the hot stage were held in a $U$-shaped peripheral ring during the azimuthal rotation (Fig. 5). Every $360^{\circ}$ the sense of rotation was reversed. For orthorhombic or higher sample symmetries the azimuthal rotation could be shortened to $90^{\circ}$, since only a quarter of the pole figure needed to be measured. This reduced the measurement time to $5 \mathrm{~min}$ for one pole figure and about $25 \mathrm{~min}$ for the determination of a full ODF (4 pole figures), respectively. This procedure could be useful for materials which undergo microstructural changes at high temperatures.

The reflected intensities could be recorded both by a scintillation detector and by a position sensitive detector. The latter is preferred when peak overlapping occur, e.g. in the ferrite + austenite region during the heating of carbon steels. 

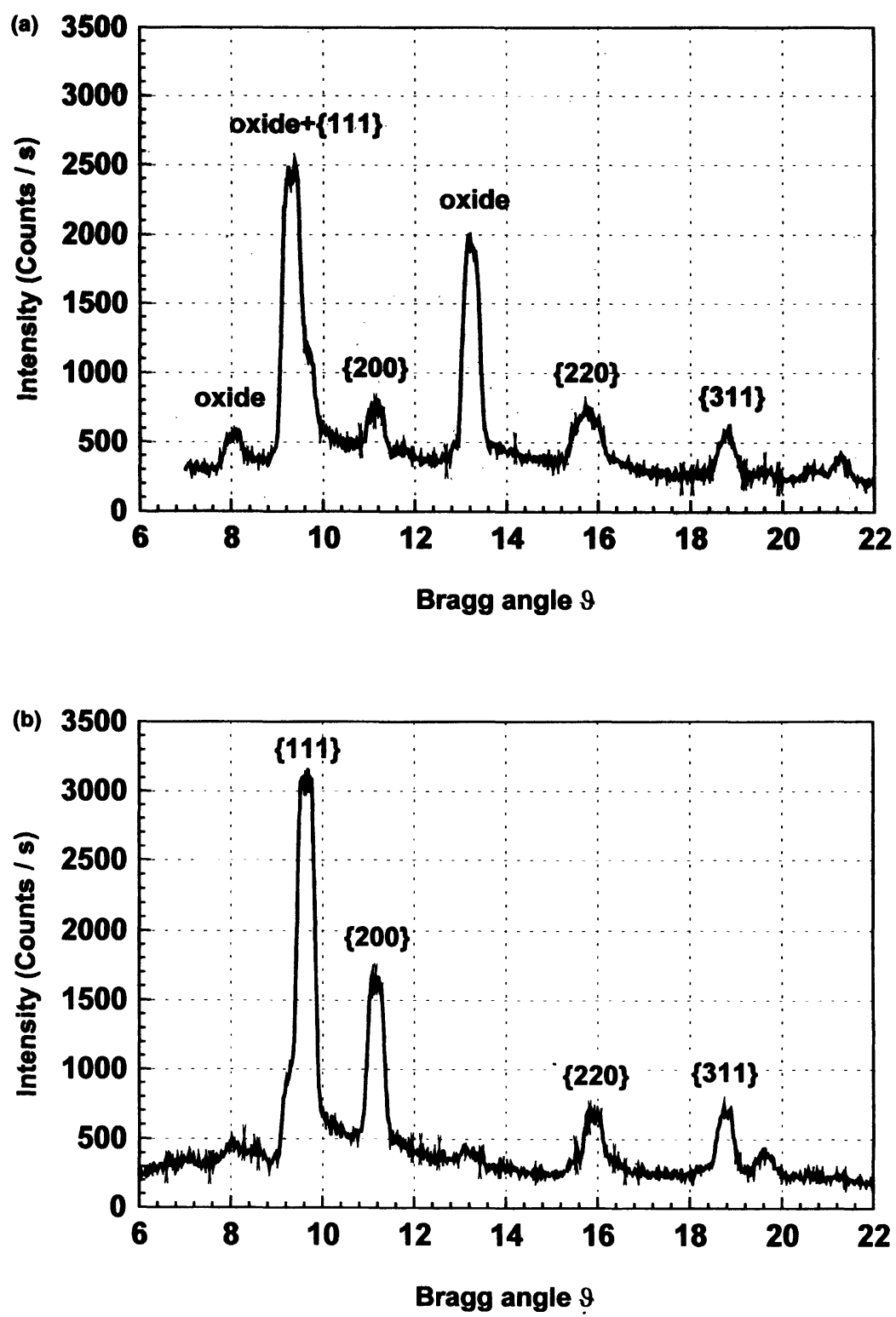

FIGURE $4 \vartheta$-scans for different gas atmospheres, $T=950^{\circ} \mathrm{C}, \mathrm{MoK}_{\alpha}$-radiation. (a) $\mathrm{N}_{2}$-gas atmosphere; (b) $\mathrm{N}_{2}+5 \% \mathrm{H}_{2}$-gas atmosphere. 


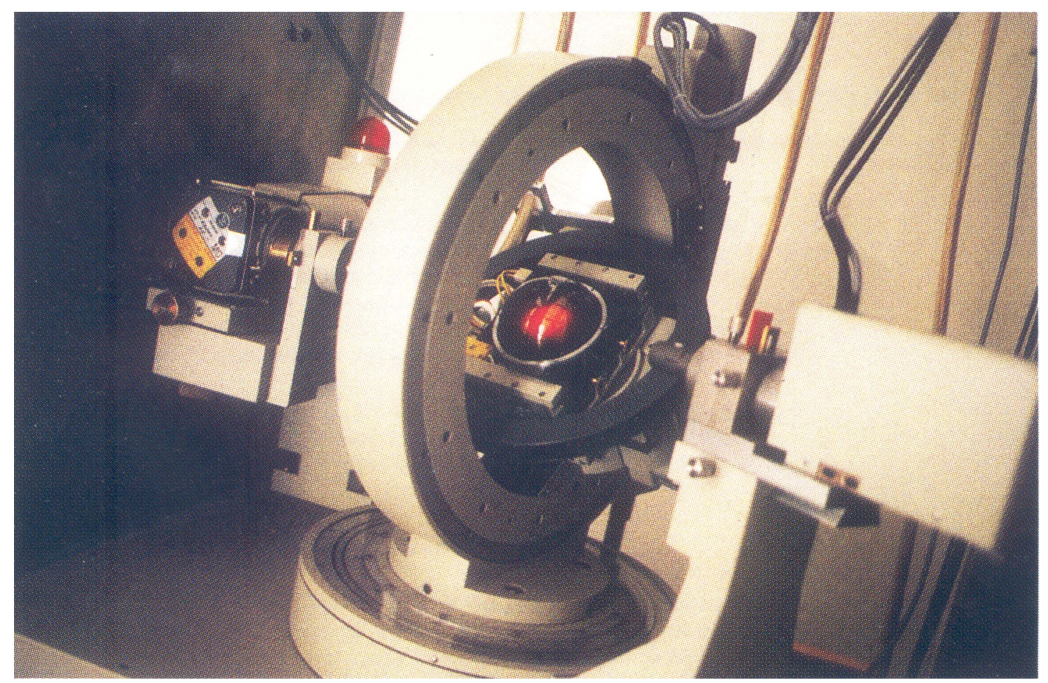

FIGURE 5 Hot furnace in the Euler cradle: the peripheral ring leads the tube and the wires during azimuthal rotation, the sense of rotation changes every $360^{\circ}$ (See Color Plate 1).

\section{SPECIFICATIONS}

specimen temperature

temperature gradients in the specimen

heating rate

specimen size

measuring surface

gas atmosphere

$X$-ray intensity

$\alpha$-latitude

$\beta$-azimuth

angular velocity $\dot{\beta}$

Bragg angle $\vartheta$
: up to $1000^{\circ} \mathrm{C}$

: $<15^{\circ} \mathrm{C}$

: $150^{\circ} \mathrm{C} / \mathrm{min}$

: $35 * 24 \mathrm{~mm}^{2}$

: $14 * 24 \mathrm{~mm}^{2}$

: $\mathrm{N}_{2}$ with $5 \% \mathrm{H}_{2}$

: $\approx 10 \%$

: $0^{\circ}-85^{\circ}$

: $0^{\circ}-360^{\circ}$

: $6 \% \mathrm{~s}$

: $5^{\circ}-56^{\circ}$

\section{Measurement speed}

single scanning step $\left(\alpha_{\mathrm{i}}, \Delta \beta_{\mathrm{i}}\right) \quad: \approx 1 \mathrm{~s}$

incomplete pole figure $\left(\alpha=5^{\circ}-85^{\circ}, \beta=0^{\circ}-360^{\circ}\right): \approx 20 \mathrm{~min}$

ODF (4 pole figures, calculation) $\quad: \approx 1.5 \mathrm{~h}$ 


\section{HIGH TEMPERATURE EXPERIMENTS}

With the equipment described above pole figures of a microalloyed low carbon steel were measured at different temperatures using $\mathrm{MoK}_{\alpha^{-}}$ radiation. At room temperature 3 incomplete BCC pole figures $\{110\}$, $\{200\}$ and $\{112\}$ were determined (Fig. 6). Subsequently the sample was automatically heated up to $950^{\circ} \mathrm{C}$ in the high temperature $\mathrm{X}$-ray goniometer. During heating the ferrit to austenit transformation took place. The $\{111\},\{200\}$ and $\{220\}$ FCC pole figures were determined at $950^{\circ} \mathrm{C}$ (Fig. 7).

The ODF's for both phases were calculated to investigate the texture transformation. Results of the in situ measurements and modelling of transformation textures are published elsewhere (Brückner, 1996a,b).
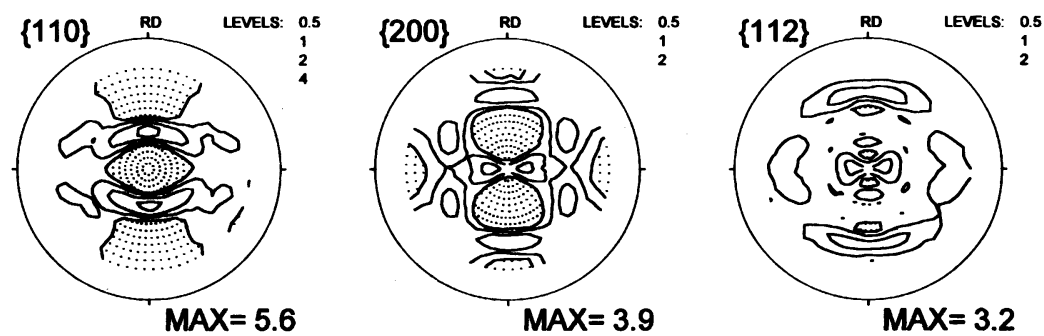

FIGURE $6\{110\},\{200\}$ and $\{112\}$ pole figures of the ferritic phase of a recrystallized, low carbon steel at $20^{\circ} \mathrm{C}\left(\mathrm{MoK}_{\alpha}\right.$-radiation, $\alpha=5^{\circ}-75^{\circ}, \beta=0^{\circ}-360^{\circ} \mathrm{C}$, measurement speed: $\approx 20 \mathrm{~min} /$ pole figure).
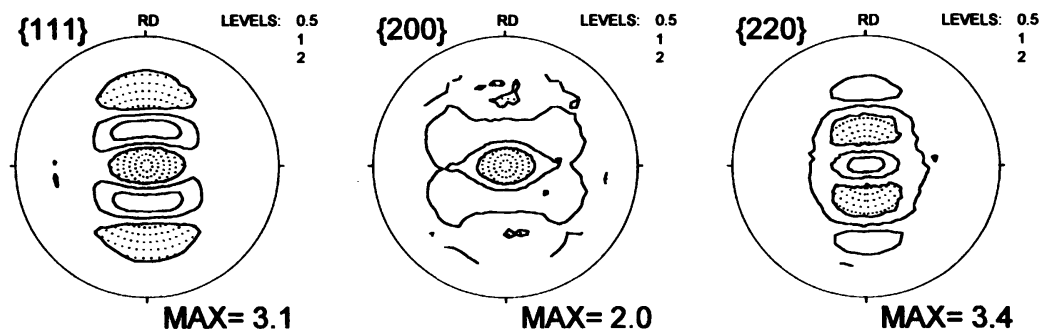

FIGURE $7\{111\},\{200\}$ and $\{220\}$ pole figures of the austenitic phase of a low carbon steel at $950^{\circ} \mathrm{C}\left(\mathrm{MoK}_{\alpha}\right.$-radiation, $\alpha=5^{\circ}-75^{\circ}, \beta=0^{\circ}-360^{\circ} \mathrm{C}$, measurement speed: $\approx 20 \mathrm{~min} /$ pole figure). 


\section{CONCLUSIONS}

The design and construction of a hot stage for a four circle X-ray texture goniometer was described. This design allowed to determine pole figures at temperatures up to $1000^{\circ} \mathrm{C}$ and to obtain the ODF in about $25 \mathrm{~min}$ (measuring four quarter pole figures). The in situ measurements are designed to study texture evolution during heating to provide a deeper understanding of texture formation during phase transformations.

\section{Acknowledgements}

The financial support of the Deutsche Forschungsgemeinschaft is gratefully acknowledged.

\section{References}

Bain, E.C. (1924) Trans. AIME 70, 25-46.

Brückner, G., Aretz, W. and Gottstein, G. (1996a) submitted to ICOTOM11, Xi'an, China.

Brückner, G. and Pospiech, J. (1996b) submitted to ICOTOM11, Xi'an, China.

Hirsch, J., Burmeister, G., Hoenen, L. and Lücke, K. (1986) in Experimental Techniques of Texture Analysis, edited by H.J. Bunge, DGM Informationsgesellschaft Verlag, pp. 63-71.

Reher, F.R., Hänel, W., Czubayko, U. and Gottstein, G. (1994) Mat. Sci. For. 157-162, 181-186. 